\title{
Recent immigrants show improved clinical outcomes at a tertiary care HIV clinic
}

\author{
Janet Raboud $\mathrm{PhD}^{1,2}$, Sandra Blitz MSc ${ }^{2}$, Tony Antoniou PharmD ${ }^{3,4}$, \\ Mona Loutfy MD MSc ${ }^{5,6}$, Sharon Walmsley MD MSc ${ }^{2,6}$
}

\begin{abstract}
J Raboud, S Blitz, T Antoniou, M Loutfy, S Walmsley. Recent immigrants show improved clinical outcomes at a tertiary care HIV clinic. Can J Infect Dis Med Microbiol 2012;23(1):9-14.
\end{abstract}

BACKGROUND: In recent years, the proportion of patients attending tertiary care HIV clinics who are recent immigrants to Canada has increased dramatically.

METHODS: Among patients first seen at the Toronto Hospital Immunodeficiency Clinic (Toronto, Ontario) between January 1, 2000 and August 31, 2009, the time to death from the first positive HIV test was compared between individuals who had immigrated to Canada within 10 years of their first visit and individuals who were either Canadian-born or who had immigrated more than 10 years before their first clinic visit. In addition, for the antiretroviral-naive patients in these two groups who initiated combination antiretroviral therapy, the time to and the duration of virologic suppression were compared.

RESULTS: In a multivariable proportional hazards (PH) model, recent immigrant status was associated with decreased mortality (HR 0.11, P=0.03) after adjusting for age, CD4 count and the risk factor for men having sex with men. In multivariable $\mathrm{PH}$ models, recent female immigrants achieved virologic suppression more quickly (HR 1.51, $\mathrm{P}=0.02$ ), while male immigrants (HR 1.14, $\mathrm{P}=0.44$ ) and female nonimmigrants (HR $0.90, \mathrm{P}=0.61$ ) had similar times to virologic suppression as male nonimmigrants, respectively, after adjusting for the year of and viral load at combination antiretroviral therapy initiation. When pregnant women were removed from the analysis, there were no significant differences in the rates of virologic rebound according to sex or immigration status.

DISCUSSION: Despite the perceived barriers of newcomers to Canada, mortality was lower among recent immigrants and virologic suppression was achieved more quickly in recent female immigrants.

Key Words: HIV; Immigration; Management; Sex

\section{De récents immigrants présentent de meilleures issues cliniques dans une clinique de soins tertiaires du VIH}

HISTORIQUE : Ces dernières années, la proportion de patients qui sont de récents immigrants au Canada et fréquentent des cliniques de soins tertiaires du VIH a considérablement augmenté.

MÉTHODOLOGIE : Chez les patients d'abord vus à la clinique d'immunodéficience du Toronto Hospital de Toronto, en Ontario, entre le $1^{\text {er }}$ janvier 2000 et le 31 août 2009, les chercheurs ont comparé le délai jusqu'au décès à compter du premier test positif du VIH entre les personnes qui avaient immigré au Canada dans les dix ans suivant leur première visite clinique et les personnes qui étaient nées au Canada ou avaient immigré plus de dix ans avant leur première visite clinique. De plus, ils ont comparé le délai jusqu'à la suppression virologique et la durée de cette suppression chez les patients naïfs aux antirétroviraux de ces deux groupes qui avaient amorcé une antirétrovirothérapie polyvalente.

RÉSULTATS : Dans un modèle de hasards proportionnels (HP) multivarié, l'état des récents immigrant s'associait à une diminution de la mortalité ( $R R$ 0,11, $\mathrm{P}=0,03$ ) après redressement selon l'âge, la numération des $\mathrm{CD}_{4}$ et le facteur de risque chez les hommes qui ont des relations sexuelles entre hommes. Dans des modèles de HP multivariés, les récentes immigrantes obtenaient une suppression virale plus rapidement ( $R R$ 1,51, $P=0,02$ ), tandis que les immigrants ( $R R 1,14, P=0,44)$ et les non-immigrantes ( $R R$ $0,90, \mathrm{P}=0,61)$ présentaient un délai similaire à celui des hommes non immigrants jusqu'à la suppression virologique, respectivement, après redressement compte tenu de l'année et de la charge virale au début de l'antirétrovirothérapie polyvalente. Lorsque les femmes enceintes étaient retirées de l'analyse, on ne constatait plus de différence significative dans les taux de rebond virologique selon le sexe ou le statut d'immigration.

EXPOSÉ : Malgré les obstacles perçus pour les nouveaux arrivants au Canada, la mortalité était plus faible chez les récents immigrants, tandis qu'on parvenait à la suppression virologique plus rapidement chez les récentes immigrantes.
$\mathrm{B}$ y December 31, 2007, 64,800 positive HIV tests had been reported to the Public Health Agency of Canada (1). While men who have sex with men (MSM) continue to account for the majority of new HIV infections in Canada (approximately 40\%), immigrants and refugees are accounting for an increasing proportion of new positive tests. This has been especially apparent since an amendment to Canadian immigration policy, introduced in 2001, rendered HIV testing mandatory for persons applying for permanent residency in Canada (2). Although people from countries endemic for HIV infection account for approximately $1.5 \%$ of the Canadian population, new HIV infections attributed to the endemic exposure category accounted for $16 \%$ of all new infections in $2005(3,4)$. These results are mirrored in Ontario, Canada's most populous province, where a $66 \%$ increase in HIV prevalence has been observed among persons from HIV-endemic regions, in the years spanning 2002 to 2007, such that these individuals now represent $17 \%$ of the HIV-infected persons in Ontario (5). Although many immigrants were likely infected before immigration, others may have been infected after their arrival.

Despite this dramatic shift in the epidemiology of HIV infection in Canada, data regarding the health services utilization and treatment outcomes associated with combination antiretroviral therapy (cART) among recent immigrants are largely lacking in the literature; an important omission given the unique needs and challenges associated with recent migration to a foreign country (6). Previous data have indicated that without standard testing, immigrants may have low selfperceived risk of HIV infection, and as a result, be diagnosed later; furthermore, because of less formal education and limited fluency, immigrants were slower to accept cART (7).

In the present study, we compared the clinical outcomes of individuals who immigrated to Canada within 10 years of their first visit to a

\footnotetext{
${ }^{1}$ Dalla Lana School of Public Health, University of Toronto; ${ }^{2}$ University Health Network; ${ }^{3}$ Maple Leaf Medical Clinic; ${ }^{4}$ St Michael's Hospital;

${ }^{5}$ Women's College Research Institute, Women's College Hospital; ${ }^{6}$ Department of Medicine, University of Toronto, Toronto, Ontario

Correspondence: Dr Janet Raboud, Toronto General Hospital, 13EN226, 200 Elizabeth Street, Toronto, Ontario M5G 2 C4.

Telephone 416-340-4137, fax 416-340-4814, e-mail jraboud@uhnresearch.ca
} 
tertiary HIV-specialist clinic with those of patients who were either Canadian-born or who had immigrated more than 10 years before their first clinic visit.

\section{METHODS}

Study population and study design

A retrospective cohort study of HIV-positive adults, who were first seen at the Toronto Hospital Immunodeficiency Clinic (THIC, Toronto, Ontario) between January 1, 2000 and August 31, 2009, was conducted. These dates were chosen because the amendment to the Canadian immigration policy was introduced in 2001; after which, the prevalence of HIV infection among recent immigrants and refugees from endemic countries began to increase in a manner that was disproportionate to their representation in the general population. The dates also include the time since the widespread introduction of cART. The THIC is a specialist-based clinic that accepts referrals from primary care physicians and refugee physicians, and is situated in a catchment area that includes a large population of immigrants and refugees from endemic countries. After the initial consultation, most patients are followed quarterly at the clinic.

There are two social workers in the clinic who assist patients with a variety of issues including housing, immigration and obtaining drug coverage. Interpreters are available in the hospital for non-English speaking patients, and referrals can be made to physicians who speak the same language, if desired. Patients are also referred to AIDS service organizations such as the Black Coalition for AIDS Prevention and Alliance for South Asian AIDS Prevention.

Antiretroviral (ARV) medications that are included in the Ontario Drug Benefit Formulary are provided free of charge for HIV-positive persons eligible for coverage with the Ontario Drug Benefit Plan (ODBP). Other avenues for accessing ARV therapy include subsidies through the provincial Trillium Drug Program, free ARVs for refugee claimants through the Interim Federal Health Program, clinical trials of new agents and, in special circumstances, patients can also access ARVs not on the provincial formulary through the Exceptional Access Program. A pharmacy, with a dedicated pharmacist for counselling, is available on site at the THIC, but its use is not mandatory.

For the analyses, patients first seen at the clinic between 2000 and 2009 were divided into two groups based on when they had arrived in Canada. Group 1 was defined as the recent immigrant group, and was comprised of individuals who had immigrated and/or been granted refugee status into Canada within 10 years of first being seen at the THIC. In contrast, group 2 was composed of individuals who were either Canadian-born or had immigrated to Canada more than 10 years before their first clinic visit. Although this group could also include immigrants and refugees who had been in Canada for more than 10 years, it is likely that these individuals had established connections in the country and were more experienced in accessing local health services when compared with individuals who had been in Canada for less than 10 years.

Ethics review for the present study was obtained by the University Health Network Ethics Review Board (Toronto, Ontario).

\section{Data collection}

Data were abstracted from the THIC research database. Laboratory data were electronically downloaded into the database from the hospital information system once per month. All other data were manually entered into the database from patient charts following each clinic visit. Patients who had not been seen in the clinic for two years were considered lost to follow-up.

\section{Study outcomes}

Three outcomes of interest were selected for the study. The first outcome was time to death from the first positive HIV test, which was compared between all patients in group 1 and group 2. Patients who were still alive were censored at the date of the most recent follow-up. The second outcome was time to virologic suppression, which was compared between antiretroviral-naive patients in group 1 and group 2. Time to virologic suppression was defined as the number of days from initiation of cART to the first date when plasma viral load (VL) was $<50$ copies/mL for two consecutive measurements. To be included in this analysis, patients were required to have a viral load $>50$ copies/mL within six months before cART initiation and at least one viral load measurement within six months after cART initiation. Participants who did not achieve virologic suppression during the study period were censored at the date of the most recent viral load measurement. The third outcome was the duration of virologic suppression, which was compared between antiretroviral-naive patients initiating cART in groups 1 and 2 who had achieved virologic suppression. The duration of virologic suppression was defined as the number of days from virologic suppression to the first of two consecutive viral load measurements $>50$ copies $/ \mathrm{mL}$. To be included in this analysis, patients were required to have at least one viral load measurement within six months after achieving virologic suppression. Patients who did not experience viral rebound during the study period were censored at the date of the most recent viral load measurement.

\section{Statistical methods}

Demographic and clinical data were summarized using frequencies and percentages for categorical data, and medians and interquartile ranges (IQR) for continuous variables. Categorical variables and continuous variables were compared between recent immigrants and other patients using $\chi^{2}$ tests and Wilcoxon rank-sum tests, respectively. Median times to virologic suppression were determined using KaplanMeier curves, and differences between the two groups, with respect to the three outcomes, were assessed using the log-rank test. Cox proportional hazards models were used to estimate the effect of recent immigration on the probability of death and the probabilities of virologic suppression and rebound, after controlling for other covariates. Analyses of time to death were left-truncated at January 1, 2000, to account for the fact that participants had to survive to that date to be included in the analysis. All statistical analyses were performed using SAS version 9.2 (SAS Institute Inc, USA). Results were considered to be statistically significant at the 0.05 level.

\section{Patient characteristics}

\section{RESULTS}

Between January 1, 2000 and August 31, 2009, a total of 1173 new patients attended the THIC, of whom 254 (22\%) had immigrated to Canada within 10 years of their first clinic visit (group 1). The median number of years between immigration and the year first seen at the clinic for these patients was 3 (IQR 1 to 7 years). The remaining 919 patients had all been in Canada for more than 10 years at the time of their first visit to the clinic. Of these 919 patients, 260 (28\%) were immigrants or refugees who had entered Canada a median of 19 years (IQR 13 to 28 years) before being first seen at the clinic.

Demographic characteristics at the time of the first clinic visit are described in Table 1 according to sex and immigration status. Individuals who immigrated within 10 years of the first clinic visit were more likely to be female, black and to have acquired HIV through heterosexual intercourse. While the recent male immigrants came from a wide range of regions around the world, almost $80 \%$ of the 135 recent female immigrants were originally from Africa. At the first clinic visit, the majority of patients in each group were ARV naive. The median baseline viral load of recent immigrants was similar to those who were Canadian-born or had immigrated more than 10 years before the first clinic visit. While the median baseline CD4 count was similar between immigrant and nonimmigrant females, the median CD4 count of immigrant males was lower than that of nonimmigrant males.

\section{Follow up}

The two groups differed with respect to median duration of follow-up from first clinic visit (3.2 years for group 1 versus 1.8 years for group 2 $[\mathrm{P}<0.001])$ and the probability of being lost to follow-up at three years ( $24 \%$ for group 1 versus $41 \%$ for group $2[\mathrm{P}<0.0001]$ ). The median 
TABLE 1

Demographic characteristics of clinic patients according to sex and immigration status

\begin{tabular}{|c|c|c|c|c|c|c|}
\hline \multirow[b]{2}{*}{ Variables } & \multicolumn{2}{|c|}{ Male } & \multirow[b]{2}{*}{$\mathbf{P}$} & \multirow{2}{*}{$\frac{\text { Female }}{\text { Immigrant }(\mathrm{n}=135)}$} & \multirow{2}{*}{$\begin{array}{c}\text { Female } \\
\text { Canadian }(n=136)\end{array}$} & \multirow[b]{2}{*}{$\mathbf{P}$} \\
\hline & Immigrant $(n=119)$ & Canadian $(n=783)$ & & & & \\
\hline Age, years, median (IQR) & $35(30-41)$ & $41(36-46)$ & $<0.0001$ & $32(28-35)$ & $36(30-44)$ & $<0.0001$ \\
\hline \multicolumn{7}{|l|}{ Risk factor } \\
\hline Injection drug use & $6(5.0)$ & $38(4.9)$ & 0.93 & $1(0.7)$ & $14(10.3)$ & $<0.001$ \\
\hline Heterosexual contact & $52(43.7)$ & $118(15.1)$ & $<0.0001$ & $87(64.4)$ & $72(52.9)$ & 0.05 \\
\hline Blood product & $8(6.7)$ & $17(2.2)$ & $<0.01$ & $10(7.4)$ & $11(8.1)$ & 0.83 \\
\hline \multicolumn{7}{|l|}{ Region of birth } \\
\hline Canada & - & $588(75.1)$ & & - & $73(53.7)$ & \\
\hline North America/Australia & $6(5.0)$ & $11(1.4)$ & & - & $1(0.7)$ & \\
\hline Central/South America & $31(26.1)$ & $27(3.4)$ & & $9(6.7)$ & $8(5.9)$ & \\
\hline Africa & 47 (39.5) & $27(3.4)$ & & $106(78.5)$ & $22(16.2)$ & \\
\hline Caribbean & $9(7.6)$ & $33(4.2)$ & & $13(9.6)$ & $20(14.7)$ & \\
\hline Caucasian & $20(16.8)$ & $426(54.4)$ & & $0(0.0)$ & $47(34.6)$ & \\
\hline Black & $51(42.9)$ & $61(7.8)$ & & $119(88.1)$ & $45(33.1)$ & \\
\hline Asian & $17(14.3)$ & $50(6.4)$ & & $3(2.2)$ & $4(2.9)$ & \\
\hline First Nations & $0(0.0)$ & $14(1.8)$ & & $0(0.0)$ & $5(3.7)$ & \\
\hline Other & $23(19.3)$ & $32(4.1)$ & & $7(5.2)$ & $7(5.1)$ & \\
\hline Data missing & $8(6.7)$ & $200(25.5)$ & & $6(4.4)$ & $28(20.6)$ & \\
\hline Year of first HIV-positive test & $2002(2000-2005)$ & 2000 (1993-2003) & $<0.0001$ & $2002(2001-2004)$ & 2001 (1996-2004) & $<0.01$ \\
\hline Year of initial clinic visit & $2004(2002-2007)$ & $2003(2001-2006)$ & $<0.01$ & $2003(2002-2005)$ & $2003(2001-2006)$ & 0.98 \\
\hline $\begin{array}{l}\text { Earliest CD4 count after initial clinic visit, cells } / \mathrm{mm}^{3} \text {, } \\
\text { median (IQR) }\end{array}$ & $235(109-413)$ & $286(147-460)$ & 0.03 & $296(164-505)$ & $321(169-486)$ & 0.83 \\
\hline $\begin{array}{l}\text { Earliest viral load after initial clinic visit, } \log _{10} \text { copies } / \mathrm{mL} \text {, } \\
\text { median (IQR) }\end{array}$ & $4.4(3.6-5.0)$ & $4.3(2.6-5.0)$ & 0.13 & $3.8(2.8-4.5)$ & $3.8(2.2-4.5)$ & 0.75 \\
\hline \multicolumn{7}{|l|}{ Antiretroviral (ARV) status } \\
\hline Started since initial clinic visit & $61(51.3)$ & $278(35.5)$ & $<0.01$ & $83(61.5)$ & $58(42.6)$ & \\
\hline \multicolumn{7}{|l|}{ Among those who started ARV before initial clinic visit } \\
\hline cART exposed & $27(87.1)$ & $213(84.2)$ & 0.67 & $19(79.2)$ & $32(74.4)$ & 0.66 \\
\hline NRTI exposed & $30(96.8)$ & $249(98.4)$ & 0.51 & $24(100.0)$ & $43(100.0)$ & \\
\hline NNRTI exposed & $19(61.3)$ & $124(49.0)$ & 0.20 & $10(41.7)$ & $18(41.9)$ & 0.99 \\
\hline Unboosted PI exposed & $9(29.0)$ & $134(53.0)$ & 0.01 & $9(37.5)$ & $21(48.8)$ & 0.37 \\
\hline Boosted PI exposed & $9(29.0)$ & $79(31.2)$ & 0.80 & $3(12.5)$ & $10(23.3)$ & 0.29 \\
\hline \multicolumn{7}{|c|}{ Initial treatment for those who began therapy after initial clinic visit } \\
\hline CART & $60(98.4)$ & $255(91.7)$ & 0.07 & $75(90.4)$ & $50(86.2)$ & 0.44 \\
\hline Included NRTI & $61(100.0)$ & $268(96.4)$ & 0.13 & $82(98.8)$ & $53(91.4)$ & 0.03 \\
\hline Included NNRTI & 39 (63.9) & $108(38.8)$ & $<0.001$ & $38(45.8)$ & $25(43.1)$ & 0.75 \\
\hline Included unboosted PI & 8 (13.1) & $49(17.6)$ & 0.39 & $14(16.9)$ & $15(25.9)$ & 0.19 \\
\hline Included boosted PI & $13(21.3)$ & $104(37.4)$ & 0.02 & $22(26.5)$ & $13(22.4)$ & 0.58 \\
\hline
\end{tabular}

Data presented as $n$ (\%), unless otherwise indicated. CART Combination antiretroviral therapy; IQR Interquartile range; NRTI Nucleoside reverse-transcriptase inhibitors; NNRTI Non-nucleoside reverse-transcriptase inhibitors; PI Protease inhibitor

numbers of viral load measurements per year were 4.47 and 4.45 for men in groups 1 and 2, respectively, and 3.87 and 4.04 for women in groups 1 and 2, respectively.

Mortality

Time to death from the first positive HIV test was compared between the two groups. In total, 62 deaths were recorded, of which 60 occurred among patients who were not recent immigrants (Figure 1). In univariate proportional hazards models, age, higher viral load at first clinic visit, ARV start date and MSM were associated with increased risks of death; while female sex, recent immigrant status and higher CD4 count at first clinic visit were associated with decreased risks of death (Table 2). In a multivariable proportional hazards model, recent immigrant status tended to be associated with lower mortality (HR 0.11 [95\% CI 0.01 to 0.80]; $\mathrm{P}=0.03$ ) after adjusting for age, CD4 count and a risk factor for MSM (Table 2). 


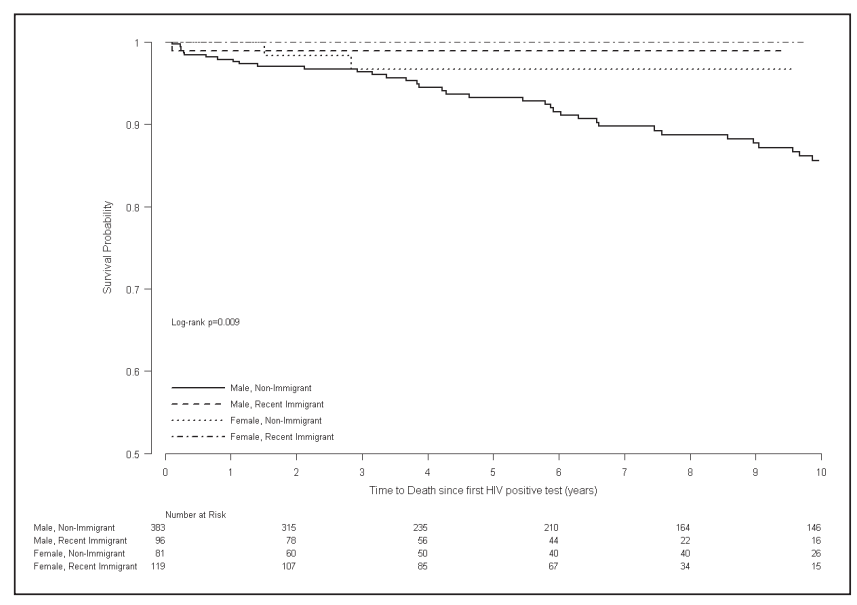

Figure 1) Kaplan-Meier curve of time to death from first positive HIV test

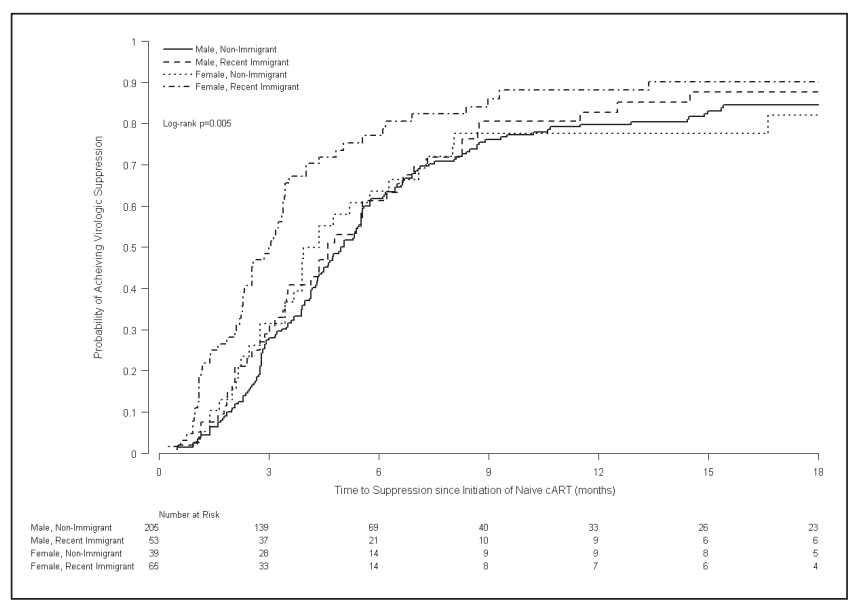

Figure 2) Kaplan-Meier curve of time to virologic suppression from initiation of naive combination antiretroviral therapy

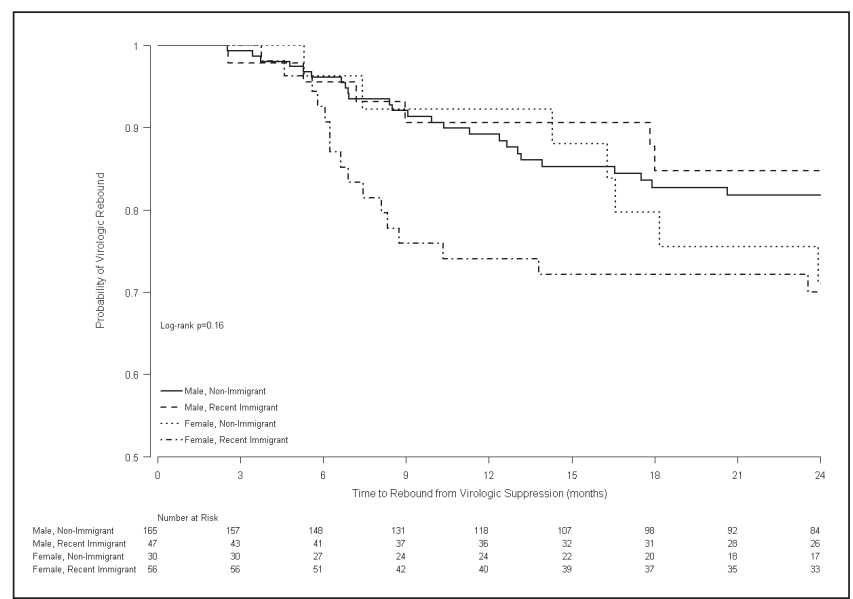

Figure 3) Kaplan-Meier curve of time to rebound from virologic suppression

\section{Virologic suppression and rebound in ARV-naive patients}

At the time of first clinic attendance, 199 of 254 (78\%) patients in group 1 and 623 of 919 (68\%) patients in group 2 were ARV naive. Of those patients, 144 (72\%) in group 1 and $336(54 \%)$ in group 2 were started on therapy after a median duration of 1.3 and 1.4 months from first clinic visit, respectively. Of the $480 \mathrm{ARV}$-naive patients initiating cART therapy, 362 had a documented viral load $>50$ copies $/ \mathrm{mL}$ at treatment initiation and had at least one viral load measurement within six months of treatment initiation and, thus, were included in the analysis.

In 19 of 141 (13\%) of the ARV-naive women, cART was initiated in the context of a pregnancy (14 of 83 [17\%] in group 1 and five of $58(8.6 \%)$ in group $2[\mathrm{P}=0.21])$. Association of cART with pregnancy was determined according to whether the year of initiation of cART coincided with the year of pregnancy or the year of the birth of the child.

At six (and 12) months after initiation of cART, 68\% (82\%) of patients in group 1 and $58 \%$ (72\%) of patients in group 2 had achieved virologic suppression to $<50$ copies/mL of HIV RNA ( $\mathrm{P}=0.07)$. Of those initiating cART, the unadjusted median time to achieve virologic suppression was 3.4 months among patients in group 1 and 4.9 months among patients in group $2(\mathrm{P}<0.006)$ (Figure 2$)$. The univariate proportional hazards models identified several variables as being associated with an increased likelihood of virologic suppression, including: higher CD4 count and lower viral load at the time of cART initiation, as well as recent immigration, year of first HIV-positive test and year of cART initiation (Table 3 ). In multivariable proportional hazards models, recent female immigrants were at an increased likelihood of achieving virologic suppression (HR $1.51[\mathrm{P}=0.02]$ ) while male immigrants and female nonimmigrants had similar likelihood as male nonimmigrants of achieving virologic suppression (HR 1.14 $[\mathrm{P}=0.44]$ and $\mathrm{HR} 0.90[\mathrm{P}=0.61]$, respectively) after adjusting for baseline viral load and year of initiation of cART. When women whose cART initiation was associated with pregnancy were excluded from the analysis, the HR of virologic suppression among immigrant women was slightly reduced (HR $1.40[\mathrm{P}=0.06]$ ).

Among the 298 patients who achieved virologic suppression and had a viral load measurement within six months following virologic suppression, subsequent virologic rebound was documented in $6 \%$ $(17 \%)$ of patients in group 1 and $4 \%(9 \%)$ of patients in group 2 at six (and 12) months $(\mathrm{P}=0.37[\mathrm{P}=0.04])$ (Figure 3$)$. In univariate proportional hazards models, female sex and higher baseline CD4 count were associated with increased risk of virologic rebound, while older age and later year of first HIV-positive test were associated with reduced risk of virologic rebound. In multivariable proportional hazards models, immigrant females (HR $1.69[\mathrm{P}=0.07]$ ) and nonimmigrant females (HR $1.93[\mathrm{P}=0.06]$ ) tended to be at increased risk of virologic rebound compared with nonimmigrant males, after adjusting for baseline CD4 count and year of initiation of cART therapy. Immigrant males $(\mathrm{HR}=1.27[\mathrm{P}=0.49])$ had similar risk of virologic rebound as nonimmigrant males. Of the 86 women included in the time to virologic rebound analysis, 11 discontinued cART in the context of pregnancy; 10 of $56(18 \%)$ in group 1 and one of $31(3 \%)$ in group 2 $(\mathrm{P}=0.09)$. When the pregnant women were excluded from the analysis, there were no significant differences in time to virologic rebound according to sex or immigration status, suggesting that discontinuing ARVs at the conclusion of a pregnancy was the reason for the increased risk of virologic rebound among women in this study population.

\section{DISCUSSION}

Recent immigrants to Canada face several obstacles including language barriers, cultural differences, uncertain immigration status, and employment and housing issues (3,7-9). An HIV diagnosis adds an additional stress, and gaining access to care and treatment provides additional challenges. In some cases, HIV-positive immigrants may be reluctant to seek care in an HIV clinic for fear of being recognized by members of their community. Despite this, our study demonstrated that clinical outcomes of recent immigrants attending the THIC were better than those of individuals who were Canadian-born or had lived in Canada for more than 10 years before their first clinic visit. When comparing all recent clinic patients, recent immigrants tended to be at lower risk of death compared with other patients, even after adjusting for age, CD4 count and viral load. Among patients who were ARV naive before their first clinic visit, recent female immigrants achieved virologic suppression more quickly than other patients. When women 
TABLE 2

Proportional hazards models of time to death from date of first positive HIV test

\begin{tabular}{|c|c|c|c|c|c|c|}
\hline \multirow[b]{2}{*}{ Covariate } & \multicolumn{3}{|c|}{ Unadjusted } & \multicolumn{3}{|c|}{ Adjusted } \\
\hline & HR & $95 \% \mathrm{Cl}$ & $\mathbf{P}$ & HR & $95 \% \mathrm{Cl}$ & $\mathbf{P}$ \\
\hline Female & 0.16 & $0.05-0.51$ & $<0.01$ & & & \\
\hline Recent immigrant & 0.12 & $0.03-0.48$ & $<0.01$ & 0.11 & $0.01-0.80$ & 0.03 \\
\hline Age (per 10 years) & 1.46 & $1.13-1.89$ & $<0.01$ & 1.52 & $1.12-2.05$ & $<0.01$ \\
\hline Male who has sex with men & 2.13 & $1.26-3.61$ & $<0.01$ & 1.83 & $1.00-3.35$ & 0.05 \\
\hline Injection drug user & 1.48 & $0.59-3.70$ & 0.40 & & & \\
\hline Coinfected with hepatitis $C$ virus & 1.67 & $0.82-3.39$ & 0.16 & & & \\
\hline First CD4 count at clinic, per 100 cells & 0.85 & $0.74-0.98$ & 0.03 & 0.85 & $0.74-0.98$ & 0.03 \\
\hline First viral load at clinic, per $\log _{10}$ copies $/ \mathrm{mL}$ & 1.35 & $1.08-1.70$ & $<0.01$ & & & \\
\hline Antiretroviral start date (time dependent) & 0.79 & $0.41-1.53$ & 0.49 & & & \\
\hline
\end{tabular}

TABLE 3

Proportional hazards models of time to virologic suppression from initiation of naive combined antiretroviral therapy

\begin{tabular}{|c|c|c|c|c|c|c|}
\hline \multirow[b]{2}{*}{ Covariate } & \multicolumn{3}{|c|}{ Unadjusted } & \multicolumn{3}{|c|}{ Adjusted } \\
\hline & HR & $95 \% \mathrm{Cl}$ & $\mathbf{P}$ & HR & $95 \% \mathrm{Cl}$ & $\mathbf{P}$ \\
\hline Female & 1.30 & $1.01-1.66$ & 0.04 & & & \\
\hline Recent immigrant & 1.39 & $1.09-1.76$ & $<0.01$ & & & \\
\hline \multicolumn{7}{|l|}{ Immigrant* sex } \\
\hline Nonimmigrant and male & 1.00 & & & 1.0 & & \\
\hline Immigrant and male & 1.13 & $0.82-1.56$ & 0.45 & 1.14 & $0.82-1.57$ & 0.44 \\
\hline Nonimmigrant and female & 0.97 & $0.66-1.41$ & 0.86 & 0.90 & $0.61-1.34$ & 0.61 \\
\hline Immigrant and female & 1.69 & $1.25-2.28$ & $<0.001$ & 1.51 & $1.08-2.10$ & 0.02 \\
\hline Age (per 10 years) & 0.93 & $0.82-1.05$ & 0.26 & & & \\
\hline Male who has sex with men & 0.83 & $0.66-1.04$ & 0.11 & & & \\
\hline Injection drug user & 0.78 & $0.45-1.37$ & 0.39 & & & \\
\hline Co-infected with hepatitis $\mathrm{C}$ virus & 0.74 & $0.48-1.14$ & 0.17 & & & \\
\hline First HIV-positive test before 2000 & 1.00 & & & & & \\
\hline $2000-2004$ & 1.62 & $1.17-2.24$ & $<0.01$ & & & \\
\hline 2005 or later & 2.09 & $1.44-3.06$ & $<0.001$ & & & \\
\hline Year of cART start & 1.08 & $1.04-1.14$ & $<0.001$ & 1.09 & $1.04-1.14$ & $<0.001$ \\
\hline NNRTI based cART & 1.23 & $0.98-1.54$ & 0.07 & & & \\
\hline Viral Load at cART start, per $\log _{10}$ copies $/ \mathrm{mL}$ & 0.78 & $0.69-0.90$ & $<0.001$ & 0.83 & $0.71-0.96$ & 0.01 \\
\hline CD4 count at cART start, per 100 cells $/ \mathrm{mm}^{3}$ & 1.10 & $1.02-1.19$ & 0.01 & & & \\
\hline
\end{tabular}

CART Combination antiretroviral therapy; NNRTI Non-nucleoside reverse-transcriptase inhibitors

TABLE 4

Proportional hazards models of time to virologic rebound since suppression

\begin{tabular}{|c|c|c|c|c|c|c|}
\hline \multirow[b]{2}{*}{ Covariate } & \multicolumn{3}{|c|}{ Unadjusted } & \multicolumn{3}{|c|}{ Adjusted } \\
\hline & HR & $95 \% \mathrm{Cl}$ & $\mathbf{P}$ & HR & $95 \% \mathrm{Cl}$ & $\mathbf{P}$ \\
\hline Female & 1.66 & $0.05-2.63$ & 0.03 & & & \\
\hline Recent immigrant & 1.36 & $0.86-2.15$ & 0.19 & & & \\
\hline \multicolumn{7}{|l|}{ Immigrant* sex } \\
\hline Nonimmigrant and male & 1.00 & & & 1.0 & & \\
\hline Immigrant and male & 1.28 & $0.66-2.49$ & 0.46 & 1.27 & $0.65-2.47$ & 0.49 \\
\hline Nonimmigrant and female & 1.82 & $0.91-3.61$ & 0.09 & 1.93 & $0.96-3.86$ & 0.06 \\
\hline Immigrant and female & 1.74 & $0.99-3.04$ & 0.05 & 1.69 & $1.43-2.68$ & 0.07 \\
\hline Age, per 10 years & 0.74 & $0.56-0.98$ & 0.04 & & & \\
\hline Male who has sex with men & 0.69 & $0.43-1.12$ & 0.13 & & & \\
\hline Injection drug user & 0.58 & $0.14-2.39$ & 0.45 & & & \\
\hline Coinfected with hepatitis $\mathrm{C}$ virus & 1.35 & $0.62-2.95$ & 0.45 & & & \\
\hline First HIV-positive test before 2000 & 1.00 & & & & & \\
\hline 2000-2004 & 0.70 & $0.41-1.22$ & 0.21 & & & \\
\hline 2005 or later & 0.38 & $0.16-0.93$ & 0.03 & & & \\
\hline Year of cART start & 0.99 & $0.88-1.10$ & 0.81 & 0.95 & $0.85-1.06$ & 0.32 \\
\hline NNRTI-based cART & 0.82 & $0.52-1.30$ & 0.40 & & & \\
\hline Viral load at cART start, per $\log _{10}$ copies $/ \mathrm{mL}$ & 0.80 & $0.62-1.03$ & 0.08 & & & \\
\hline CD4 count at cART start, per 100 cells $/ \mathrm{mm}^{3}$ & 1.28 & $1.14-1.44$ & $<0.0001$ & 1.31 & $1.16-1.48$ & $<0.001$ \\
\hline
\end{tabular}

cART Combination antiretroviral therapy; NNRTI Non-nucleoside reverse-transcriptase inhibitors 
who initiated CART in the context of a pregnancy were excluded from the analysis, the advantage of recent female immigrants over other groups was reduced somewhat, suggesting that at least part of the increased virologic response was due to improved adherence among pregnant women.

Differences in mortality may be related to differences in demographic and clinical characteristics between recent immigrants and longer-term residents of Canada. Routine testing at the time of immigration, and during pregnancy, could result in recent immigrants being diagnosed at an earlier stage of HIV disease than other patients. Although we did not have sufficient data on viral clade to test this hypothesis, it is possible that part of the differences in mortality and time to suppression could be due to differences in clades between the immigrant and nonimmigrant patients. While there is no evidence that different clades respond differently to initial ARV $(6,10,11)$, some studies have shown an effect of viral clade on mortality $(6,12)$. A higher proportion of recent immigrants were female, which may have been related to clinical outcomes, although previous clinical trials involving ARV-naive subjects have not been powered sufficiently to address sex differences (13).

Further differences in mortality and time to virologic suppression may be due to improved adherence among recent immigrants (14). There were no adherence data available to confirm this hypothesis, but the longer duration of follow-up and lower rates of loss to follow-up observed in the new immigrants might indicate higher rates of adherence to medical care and treatment. Adherence to ARV medication could be higher among recent immigrants due to several factors including: motivation by infected partners or children to maintain their health, a desire to reduce the risk of vertical transmission, the perception that an improved immune status would improve their immigration opportunities or the lower rate of injection drug use as a risk factor, especially in women. Furthermore, recent immigrants to Canada from countries with a high prevalence of HIV may have a heightened state of awareness of the ramifications of untreated HIV infection relative to individuals who have lived in Canada for more than 10 years and for whom HIV/AIDS-associated deaths are no

\section{REFERENCES}

1. Public Health Agency of Canada. HIV and AIDS in Canada: Surveillance Report to December 31, 2007. Surveillance and Risk Assessment Division, Center for Communicable Diseases and Infection Control. <www.phac-aspc.gc.ca/aids-sida/publication/ survreport/index-eng.php> (Accessed on September 16, 2009).

2. Citizenship and Immigration Canada. Immigrant and Refugee Protection Act. Statues of Canada 2001 (Chapter 27).

3. Krentz H, Gill MJ. The five-year impact of an evolving global epidemic, changing migration patterns, and policy changes in a regional Canadian HIV population. Health Policy 2009;90:296-302.

4. Public Health Agency of Canada. HIV in Canada among persons from countries where HIV is endemic. In: HIV/AIDS Epi updates, November 2007. Surveillance and Risk Assessment Division, Center for Infectious Disease Prevention and Control, Ottawa: Public Health Agency of Canada, 2007.

5. Remis RS, Swantee C, Liu J. Report on HIV/AIDS in Ontario 2007. < www.phs.utoronto.ca/ohemu/doc/PHERO2007_report_final. pdf> (Accessed on September 16, 2009).

6. Taylor BS, Sobieszczyk ME, McCutchan FE, Hammer SM. The challenge of HIV-1 subtype diversity. N Engl J Med 2008;358:1590-602.

7. Foley EE. HIV/AIDS and African immigrant women in Philadelphia: Structural and cultural barriers to care. AIDS Care 2005;17:1030-43.

8. Saracino A, El-Hamad I, Prato R, et al. Access to HAART in HIV-infected immigrants: A retrospective multicenter Italian study. AIDS Patient Care \& STDS 2005;19:599-606.

9. Cohen M, Arad S, Lorber M, et al. Psychological distress, life stressors, and social support in new immigrants with HIV. Behav Med 2007;33: 45-54. longer the norm. Finally, recent immigrants and refugees may represent a highly motivated group of individuals, many of whom overcame significant obstacles in emigrating from their country of origin to Canada. It is, therefore, possible that a selection bias is introduced by examining recent immigrants in care, because these individuals may exhibit attitudes and behaviours that portend an increased likelihood for good outcomes. Strong social support is considered to be powerful protection against psychological distress among members of immigrant minority groups and relates to better adherence to ARV therapy. Data exist that indicate women are more likely to seek support, and are more inclined to use it and benefit from it then men (15).

Other centres have also documented sharp increases in the proportion of immigrants among their HIV-infected population (16). In other settings, changes in CD4 counts, rates of adherence to cART, progression to AIDS or survival to 48 months after starting therapy have been shown to be similar between immigrant and nonimmigrant populations $(11,16)$. Economic analyses have demonstrated that migrants had fewer hospitalizations, more frequent outpatient visits and lower total cost of care per year of follow-up (17). Systematic screening was hypothesized to identify HIV-positive patients earlier, and hence, give them access to effective therapy in a more timely fashion.

Our study has the limitation of being a single-centre study. Because we only considered individuals who were referred to a tertiary care HIV clinic, our study population may not be reflective of the HIV-positive population in Ontario. Future plans for investigation could include the addition of other cohorts to the analysis to enable verification of the findings in other settings and an increase of the sample size, which may enable the trend for statistical significance of the mortality outcome to reach significance. Further investigation into the habits of immigrant women compared with nonimmigrant women, immigrant men and nonimmigrant men may assist in improving care for the latter three groups.

ACKNOWLEDGEMENTS: JM Raboud and SL Walmsley were supported by Ontario HIV Treatment Network Career Scientist Awards while MR Loutfy was supported by a CIHR Salary Award. T Antoniou was supported by a CANOC Fellowship.
10. Spira S, Wainberg MA, Loemba $\mathrm{H}$, et al. Impact of clade diversity on HIV-1 virulence, antiretroviral drug sensitivity and drug resistance. J Antimicrob Chemother 2003;51:229-40.

11. De Arellano ER, Benito JM, Soriano V, et al. Impact of ethnicity and HIV type 1 subtype on response to first-line antiretroviral therapy. AIDS Res Hum Retroviruses 2007;23:891-4.

12. Anastassopoulou CG, Kostrikis LG. Viral correlates of HIV-1 disease. Curr HIV Res 2005;3:113-32.

13. Struble K, Soon G, Min M, et al. Meta-analysis of efficacy outcomes for treatment-naive and treatment-experienced HIV-infected women in randomized controlled clinical trials: 2000 to 2008 (Abstract 987B). Presented at the 16th Conference on Retroviruses and Opportunistic Infections, February 8 to 11, Montreal, 2009.

14. Lima VD, Harrigan R, Bangsberg DR, et al. The combined effect of modern highly active antiretroviral therapy regimens and adherence on mortality over time. J AIDS 2009;50:529-36.

15. Patterson, T, Semple SJ, Temoshok L, et al. Stress and depressive symptoms prospectively predict immune change among HIV-seopositive men. Psychiatry 1995;58:299-312.

16. Staehelin C, Rickenbach M, Low N, et al. Migrants from Sub-Saharan Africa in the Swiss HIV Cohort Study: Access to antiretroviral therapy, disease progression and survival. AIDS 2003,17:2237-44.

17. Wasserfallen JB, Hyjazi A, CavassiniM. Comparison of HIV-infected patients' characteristics, healthcare resources use and cost between native and migrant patients. Int J Public Health 2009;54:5-10. 


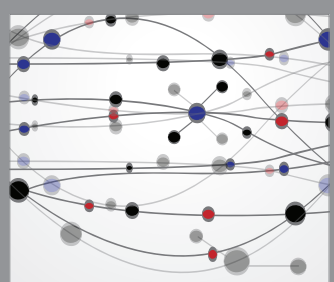

The Scientific World Journal
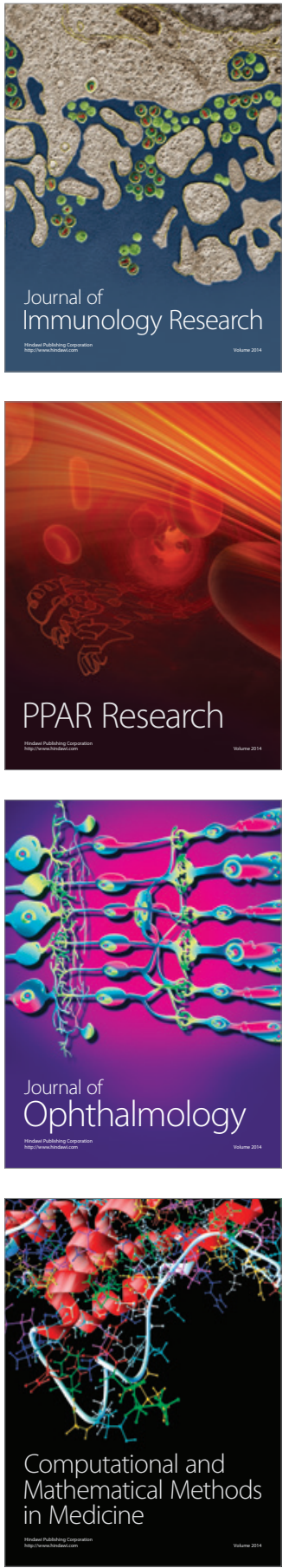

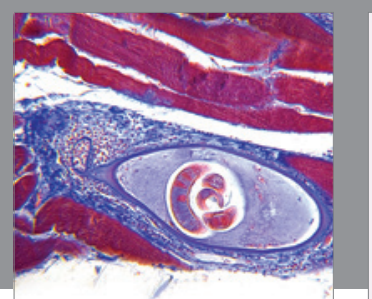

Gastroenterology Research and Practice

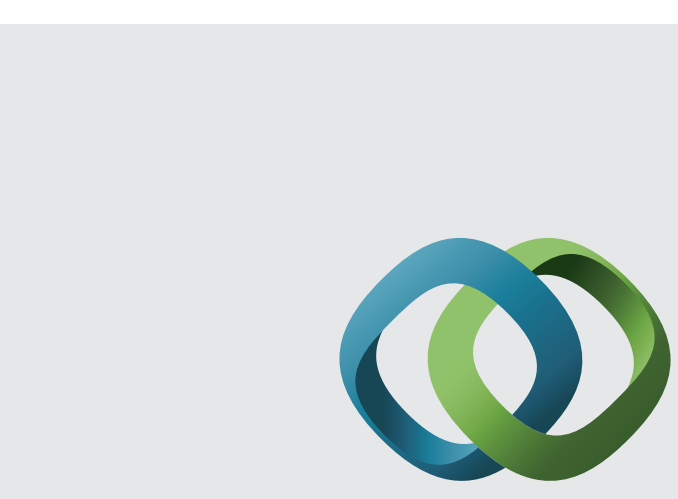

\section{Hindawi}

Submit your manuscripts at

http://www.hindawi.com
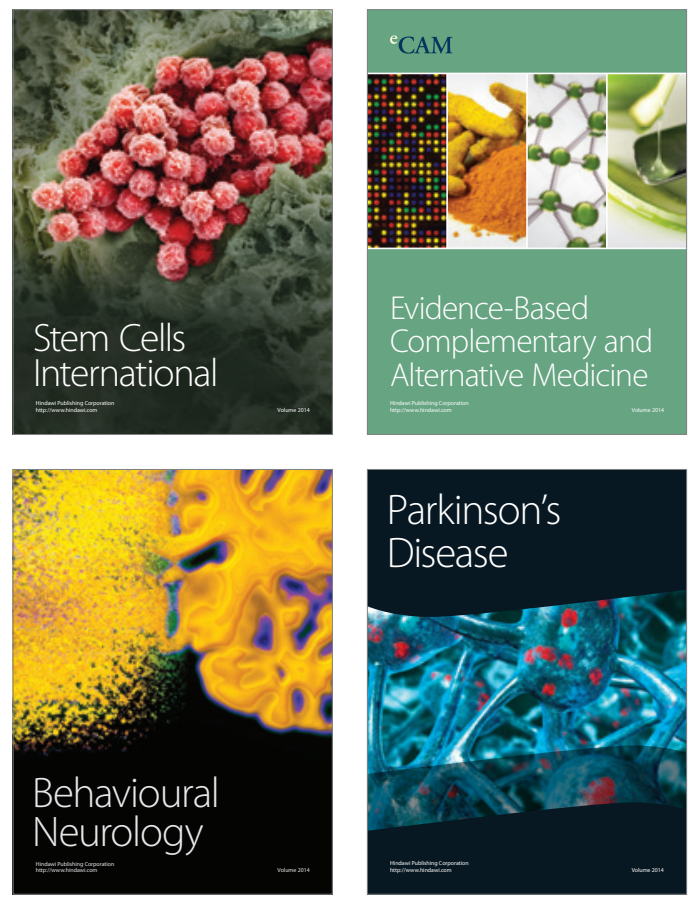
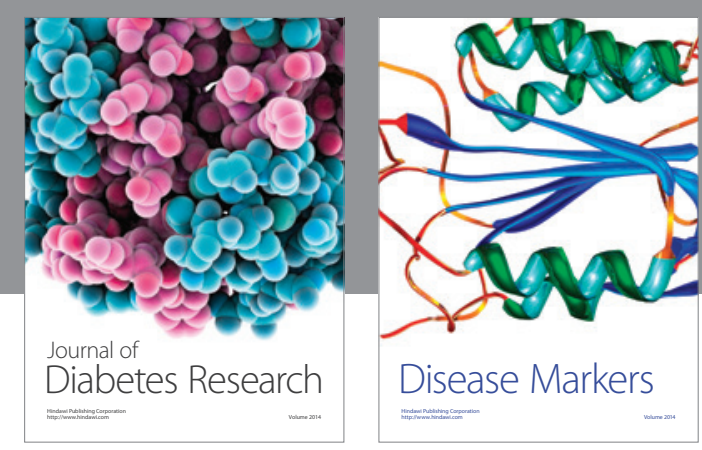

Disease Markers
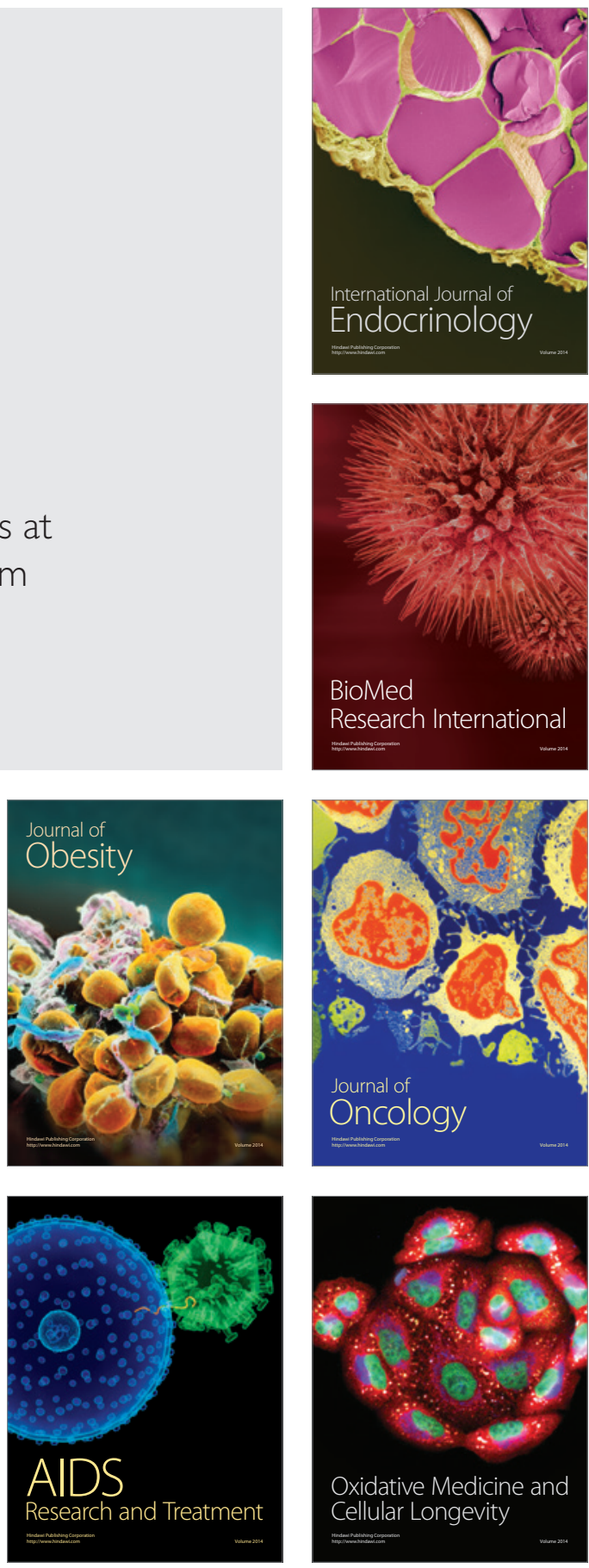